\title{
Continuous flow nanocatalysis: reaction pathways in the conversion of levulinic acid to valuable chemicals
}

Jose M. Bermudez ${ }^{\mathrm{a}, \mathrm{b}}$, J. Angel Menéndez ${ }^{\mathrm{b}}$, Antonio A. Romero ${ }^{\mathrm{a}}$, Elena Serrano ${ }^{\mathrm{c}}$, Javier Garcia-Martinez $^{\mathrm{c}}$ and Rafael Luque ${ }^{\mathrm{a} *}$

${ }^{a}$ Departamento de Química Orgánica, Universidad de Córdoba, Edif. Marie Curie, Ctra Nnal IV-A, Km 396,E14014, Córdoba (Spain),E-mail: q62alsor@uco.es

${ }^{b}$ Instituto Nacional del Carbón, CSIC, Apartado 73, 33080 Oviedo, Spain ${ }^{c}$ Molecular Nanotechnology Lab., Department of Inorganic Chemistry, University of Alicante, Carretera San Vicente s/n, E-03690 Alicante, Spain.

\begin{abstract}
The selective production of 2-methylterahydrofuran from levulinic acid has been effectively conducted using designed $\mathrm{Cu}$ based catalysts and compared with a commercial $\mathrm{Pd} / \mathrm{C}$ system under microwave irradiation. Optimised conditions for the most active catalysts $\mathrm{Cu}-\mathrm{MINT}$ ( $>90 \%$ conversion, $75 \%$ selectivity to $\mathrm{MTHF}$ ) and $\mathrm{Pd} / \mathrm{C}$ (78\% conversion, $92 \%$ selectivity to MTHF) were further translated into a continuous flow process using the proposed catalysts to find out a deactivation of $\mathrm{Cu}-\mathrm{MINT}$ under flow conditions ( 79 vs $13 \%$ conversion with a switch in selectivity to products after 30 min in flow), a high stability of $\mathrm{Pd} / \mathrm{C}$ ( 73 vs $70 \%$ conversion at stable selectivity under analogous conditions to those of $\mathrm{Cu}-\mathrm{MINT}$ ) but most importantly relevant varying pathways to valuable products from levulinic acid depending on the type of catalyst employed.
\end{abstract}




\section{Introduction}

Biomass-derived platform molecules are key compounds with mutiple functionalities that have the potential to be converted into a wide range of high added value chemicals. ${ }^{1}$ These building blocks including a variety of sugars, (poly)alcohols and organic acids have attracted a significant interest in recent years in order to switch towards a more biobased focused production of chemicals, fuels and materials. Important platform molecules include glycerol, sugars (sorbitol, xylitol/arabinitol), ethanol as well as furan-derived compounds and succinic, itaconic, fumaric and levulinic acids. ${ }^{1,2}$

Recent research endeavours have been focused on $\mathrm{C} 4$ and $\mathrm{C} 5$ organic acids as these constitute a promising family of chemicals from which relevant end products can be derived including polymers, solvents, flame retardants, food additives, cosmetics and related comodities. ${ }^{1,2}$ Levulinic acid has been identified as a key platform chemical for the production of high added value derivatives including 1,4-pentanediol (as intermediate for biopolymers ${ }^{3}$ ), $\gamma$ valerolactone (as key compound for the production of biofuels and biopolymers ${ }^{4}$ ) and 2-methyltetrahydrofuran (as potential biofuel ${ }^{5}$ and alternative green solvent for the pharmaceutical industry ${ }^{6}$ ).

Particularly related to the conversion of 2-methyltetrahydrofuran (MTHF) from levulinic acid (LA), recent work showed this relevant chemical could be obtained in different yields and selectivities replacing noble metals by the use of cheaper, equally performing and more environmentally friendly catalysts, generally under relatively high hydrogen pressures ( $>50$ bar). ${ }^{7}$ These have been also carried out both in the liquid phase (30 $\mathrm{wt} \% \mathrm{Cu}$-zirconia catalysts, $94 \%$ conversion, $93 \%$ selectivity to MTHF after $6 \mathrm{~h}$ at $\left.240^{\circ} \mathrm{C}\right)^{7 \mathrm{a}}$ as well as in the gas phase $\left(80 \mathrm{wt} \% \mathrm{Cu} / \mathrm{SiO}_{2}, 64 \% \text { yield } \mathrm{MTHF} \text { at } 265^{\circ} \mathrm{C}\right)^{7 \mathrm{~b}}$. 
The use of homogeneous Ru systems could also provide excellent yields of MTHF after $18 \mathrm{~h}$ at $195^{\circ} \mathrm{C}$, in which a promising continuous flow system for the production MTHF from LA could be envisaged. ${ }^{8}$ Nevertheless, a quick check at reported catalysts, reaction conditions and processes clearly indicates that reported results to date can be optimised and catalytic systems should be carefully designed to minimise catalyst/metal loading maximisising at the same time MTHF yields from LA at the milder possible reaction conditions. MTHF is converted from LA in a multistep sequence (Scheme 1). The process involves cyclisation of LA via hydrogenation/dehydration to $\gamma$ valerolactone (GVL), subsequent direct hydrogenation to MTHF as well as hydrogenation to 1,4 pentanediol (PDO) and eventual dehydration/cyclisation to MTHF (Scheme 1). The chemistries involved in the production of MTHF are essentially hydrogenations that take place over metallic sites as well as a potential minor contribution of acid sites in dehydration reactions (especially from PDO to MTHF).
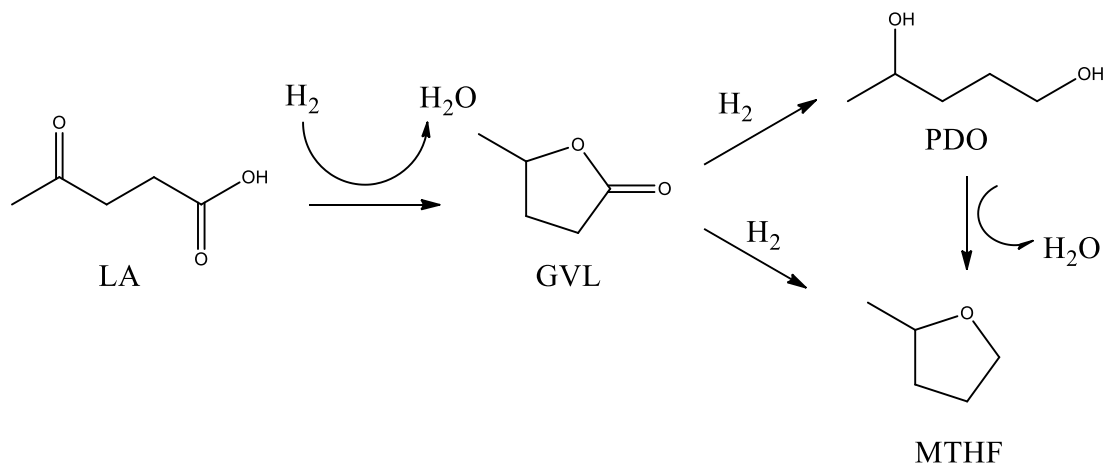

Scheme 1. Reaction pathway for the production of MTHF from LA.

Following our recent findings related to the use of formic acid as hydrogendonating media in heterogeneously-catalysed lignin depolymerisations ${ }^{9}$ in line with recent literature reports, ${ }^{10}$ this proposed proof-of-concept was aimed to avoid the use of high $\mathrm{H}_{2}$ pressures in the systems by using formic acid (FA) as hydrogen-donating solvent combined with a suitably designed nanocatalytic system able to selectively 
convert LA into MTHF in high yields. FA is known to readily decompose into $\mathrm{CO}_{2}$ and $\mathrm{H}_{2}$ under temperature and pressure, a process that is accelerated in the presence of appropiate catalysts. $^{11}$

In this way, we will be able to mimic a plausible biomass scenario in which cellulose from forestry residues (e.g. lignocellulosics) is hydrolysed to glucose and then to LA and FA via dehydration. This FA co-generated in the dehydration process could be then utilised in a similar way to that proposed in our approach for the sustainable and selective production of GVL, PDO or MTHF using appropriately designed catalysts (Scheme 2).

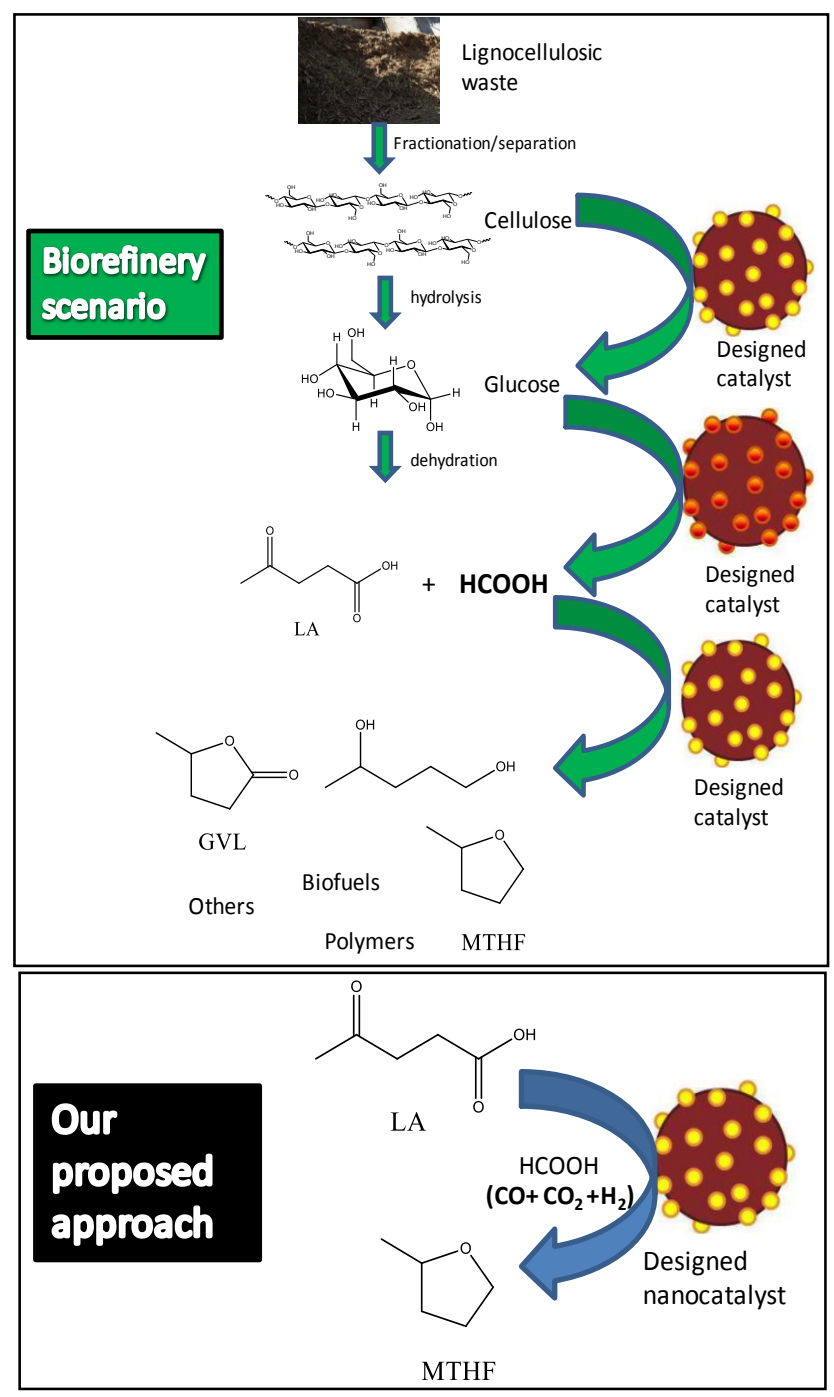

Scheme 2. Proposed approach from this work as compared to a theoretical biorefinery concept on cellulose valorisation. 
The final goal of the proposed concept will be the translation of optimised results into a more scalable continuous flow process. To the best of our knowledge, there are no available literature reports on the liquid-phase continuous flow production of MTHF from LA in a one-pot multistep reaction.

\section{Experimental}

\section{Synthesis of materials}

\section{Materials preparation Metal-Starbons}

The preparation of supported metal nanoparticles (SMNPs) on Starbons was carried out using a previously reported simple facile impregnation/reduction methodology ${ }^{1}$. Starbons ${ }^{\circledR}$ were suspended in a ethanol/(acetone) solution of the metal precursor $(\mathrm{Ru}$ and $\mathrm{Rh}$ chlorides, palladium acetate) containing the theoretical metal loading ( $5 \mathrm{wt} \%$ metal) and stirred under mild heating $\left(45-55^{\circ} \mathrm{C}\right)$ overnight. The final solid containing MNPs was then vacuum filtered, washed thoroughly with fresh acetone and activated in a vacuum oven at $45-60^{\circ} \mathrm{C}$ overnight.

\section{Preparation of $\mathrm{Cu}-\mathrm{MINT}$}

In a typical synthesis, $0.6 \mathrm{mmol} n$-dodecylamine $(0.14 \mathrm{~mL}), 2 \mathrm{mmol}$ tetraethoxyorthosilicate (TEOS, $0.45 \mathrm{~mL}$ ), $0.2 \mathrm{~g} \mathrm{CuCl}_{2} .4 \mathrm{H}_{2} \mathrm{O}, 2 \mathrm{~mL}$ water and $2 \mathrm{~mL}$ acetonitrile were added to a microwave tube and microwaved for $5 \mathrm{~min}$ at $200 \mathrm{~W}$ (maximum temperature reached $80^{\circ} \mathrm{C}$ ). The resultant silica material (light blue coloured) was filtered off, thoroughly washed with acetonitrile and acetone to remove all physisorbed $\mathrm{Cu}$ species and dried overnight at $100^{\circ} \mathrm{C}$ before the template was extracted in refluxing ethanol $(5 \mathrm{~h})$. Materials were then oven dried $\left(100^{\circ} \mathrm{C}\right)$ overnight prior to their use in the catalytic reaction. The material was denoted as $\mathrm{Cu}-\mathrm{MINT}$ where 
MINT stands for Microwave Induced Nanotubes, which can be clearly seen in their corresponding TEM images. ${ }^{12}$

$5 \% \mathrm{Pd} / \mathrm{C}$ and $13 \mathrm{wt} \% \mathrm{CuO} / \mathrm{Al}_{2} \mathrm{O}_{3}$ materials were commercially available catalysts from Thalesnano Inc. at http://www.thalesnano.com/products/catcart.

\section{Materials characterisation}

Nitrogen adsorption measurements were carried out at $77 \mathrm{~K}$ using an ASAP 2010 volumetric adsorption analyzer from Micromeritics. The samples were outgassed for $2 \mathrm{~h}$ at $100^{\circ} \mathrm{C}$ under vacuum $\left(\mathrm{p}<10^{-2} \mathrm{~Pa}\right)$ and subsequently analyzed. The linear part of the BET equation (relative pressure between 0.05 and 0.22 ) was used for the determination of the specific surface area. The pore size distribution was calculated from the adsorption branch of the $\mathrm{N}_{2}$ physisorption isotherms and the Barret-JoynerHalenda (BJH) formula. The cumulative mesopore volume $\mathrm{V}_{\text {ВJH }}$ was obtained from the PSD curve.

TEM micrographs were recorded on a FEI Tecnai $\mathrm{G}^{2}$ fitted with a CCD camera for ease and speed of use. The resolution is around $0.4 \mathrm{~nm}$. Samples were suspended in ethanol and deposited straight away on a copper grid prior to analysis.

XPS (aka ESCA) measurements were performed in an ultra high vacuum (UHV) multipurpose surface analysis system (Specs ${ }^{\mathrm{TM}}$ model, Germany) operating at pressures $<10^{-10}$ mbar using a conventional X-Ray source (XR-50, Specs, Mg-Ka, $1253.6 \mathrm{eV}$ ) in a "stop-and-go" mode to reduce potential damage due to sample irradiation. The survey and detailed $\mathrm{Fe}$ and $\mathrm{Cu}$ high-resolution spectra (pass energy 25 and $10 \mathrm{eV}$, step size 1 and $0.1 \mathrm{eV}$, respectively) were recorded at room temperature with a Phoibos 150-MCD energy analyser. Powdered samples were deposited on a sample holder using doublesided adhesive tape and subsequently evacuated under vacuum $\left(<10^{-6}\right.$ Torr $)$ overnight. 
Eventually, the sample holder containing the degassed sample was transferred to the analysis chamber for XPS studies. Binding energies were referenced to the $\mathrm{C} 1 \mathrm{~s}$ line at $284.6 \mathrm{eV}$ from adventitious carbon.

The metal content in the materials was determined using Inductively Coupled Plasma (ICP) in a Philips PU 70000 secuential spectrometer equipped with an Echelle monochromator (0.0075 nm resolution) couple with mass spectrometry. Samples were digested in $\mathrm{HNO}_{3}$ and subsequently analysed by ICP at the SCAI in Universidad de Cordoba.

\section{Catalytic experiments}

\section{Microwave-assisted reactions}

Microwave-assisted reactions were conducted on for a period of time (typically $30 \mathrm{~min}$ ) at $150^{\circ} \mathrm{C}$ under continuous stirring. In a typical experiment, $0.1 \mathrm{~mL}$ levulinic acid, 0.3 $\mathrm{mL}$ formic acid (containing $<5 \%$ water) and $0.1 \mathrm{~g}$ catalyst were microwaved at $150^{\circ} \mathrm{C}$ for $30 \mathrm{~min}(300 \mathrm{~W}$, maximum power output) on a pressure-controlled CEM-Discover microwave reactor equipped with PC control. Upon reaction completion, samples were then withdrawn from the reaction mixture and analysed by GC and GC/MS Agilent $6890 \mathrm{~N}$ fitted with a capillary column HP-5 $(30 \mathrm{~m} \times 0.32 \mathrm{~mm} \times 0.25 \mu \mathrm{m})$ and a flame ionisation detector (FID). The identity of the products was confirmed by GC-MS and ${ }^{1} \mathrm{H}$ and ${ }^{13} \mathrm{C}$ NMR. Response factors of reaction products were determined from GC analysis using standard compounds in calibration mixtures of specified compositions.

\section{Flow reactions}

Flow reactions were conducted on a X-Cube instrument from Thalesnano Inc. equipped with back pressure regulator. A solution of FA $\left(0.3 \mathrm{~mL},<5 \% \mathrm{H}_{2} \mathrm{O}\right)$ and 0.1 
$\mathrm{mL}$ LA were circulated at a flow rate of $0.1 \mathrm{~mL} \mathrm{~min}^{-1}$ through a fixed bed at $150^{\circ} \mathrm{C}$, containing $0.25 \mathrm{~g}$ catalyst (feed/catalyst contact time: $1 \mathrm{~min}$ ). The reaction mixture was analysed in a similar way to that described for the microwave experiments. Full experimental details for synthesis and reactions have been included in detail at the ESI.

Typical experimental errors were found within $5 \%$ of total given values.

\section{Results and discussion}

Inspired by previous reports in the production of MTHF from LA that employed $\mathrm{Cu}$-based catalysts, ${ }^{7}$ we designed a simple and efficient nanocatalytic $\mathrm{Cu}$-containing silica material based on previous reports from the group. ${ }^{12}$ The synthesis of the material comprised a one-pot addition of template (n-dodecylamine), silica source (tetraehtylorthosilicate, TEOS) and metal precursor $\left(\mathrm{CuCl}_{2} \cdot 4 \mathrm{H}_{2} \mathrm{O}\right)$ in an aqueous/ethanol/acetonitrile solution followed by microwave irradiation for 3-5 min to yield a blue coloured nanocatalyst featuring embedded nanoparticles on the silica matrix upon extraction of the organic template by ethanol refluxing. ${ }^{12}$ The final material possessed a high surface area $\left(>500 \mathrm{~m}^{2} \mathrm{~g}^{-1}\right)$, pore volume and a pore diameter in the micropore range (Table 1).

A series of metal containing mesoporous carbonaceous Starbon ${ }^{\circledR}$ materials have also been investigated in this work (Table 1) based on previous reported high activities for the transformation of bio based chemicals (e.g. hydrogenation of succinic acid to 1,4 butanediol, $\gamma$ butyrolactone and tetrahydrofuran). ${ }^{13}$ Depending on the catalyst, metal nanoparticles with nanoparticle sizes in the 2.5 to $9 \mathrm{~nm}$ range were observed (Figure 1 and ESI). Metal loadings from all metal Starbon ${ }^{\circledR}-300$ materials was in the 4.1 to 4.9 wt.\% range while $\mathrm{Cu}$ MINT contained 0.51 wt. $\% \mathrm{Cu}$ (mostly as $\mathrm{Cu}^{2+}$ species). ${ }^{12}$ 
Table 1. Textural properties, metal content and nanoparticle(NP) sizes of investigated supported nanoparticle systems in this work.

\begin{tabular}{lccccc}
\hline Catalyst & $\begin{array}{c}\text { Surface } \\
\text { area } \\
\left(\mathrm{m}^{-1} \mathrm{~g}^{-1}\right.\end{array}$ & $\begin{array}{c}\text { Pore } \\
\text { diameter } \\
(\mathrm{nm})\end{array}$ & $\begin{array}{c}\text { Pore } \\
\text { volume } \\
\left(\mathrm{mL} \mathrm{g}^{-1}\right)\end{array}$ & $\begin{array}{c}\text { Metal } \\
\text { content } \\
(\text { wt.\%) }\end{array}$ & $\begin{array}{c}\text { NP } \\
\text { size } \\
(\mathrm{nm})\end{array}$ \\
\hline Ru-Starbon ${ }^{\circledR}$ & 240 & 16.9 & 0.49 & 4.11 & 2.7 \\
Rh-Starbon ${ }^{\circledR}$ & 256 & 17.0 & 0.52 & 4.32 & 8.5 \\
Pd-Starbon ${ }^{\circledR}$ & 201 & 16.7 & 0.49 & 4.87 & 8.9 \\
Cu-MINT & 586 & $<1.5$ & 0.25 & 0.51 & 2.5 \\
\hline
\end{tabular}

[a] Starbon ${ }^{\circledR}-300$ materials were selected as supports due to their water tolerant properties $^{14}$
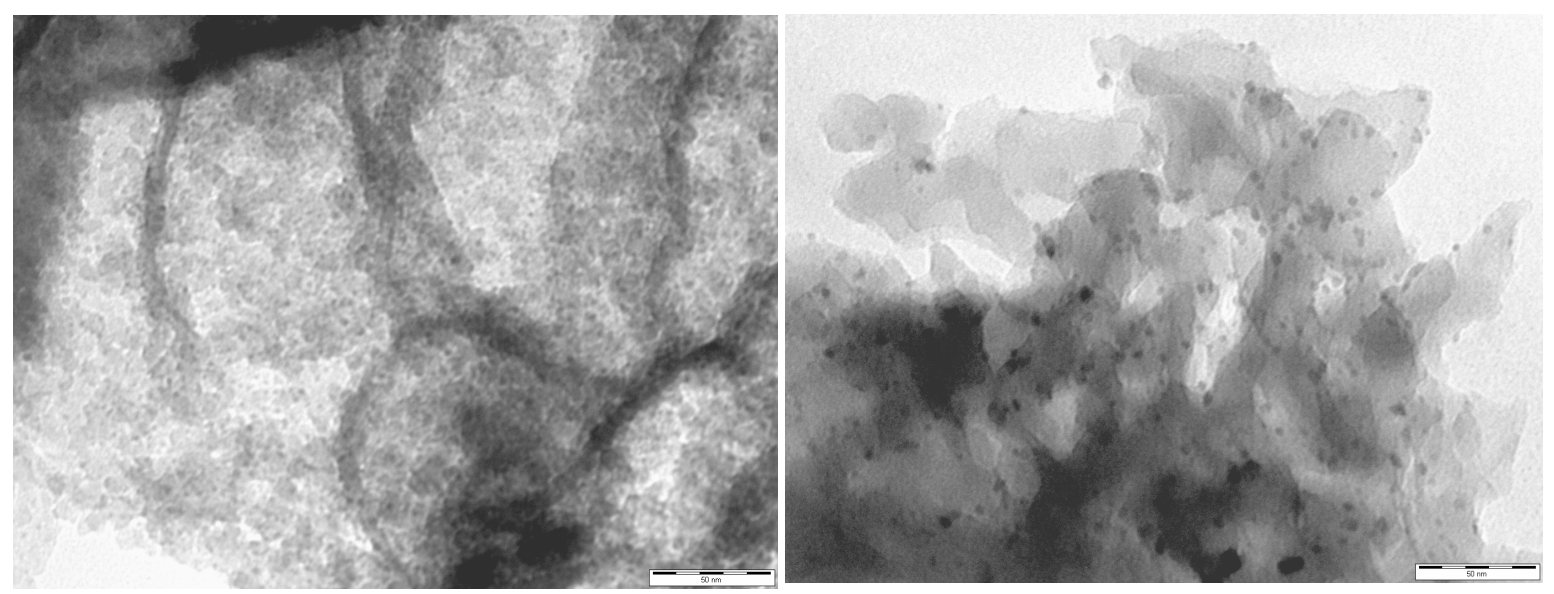

Figure 1. TEM micrographs of Cu-MINT (left image) as compared to a metal containing Starbon ${ }^{\circledR}$ (right image, Pd-Starbon ${ }^{\circledR}$ ). Scale bars: $50 \mathrm{~nm}$.

A summary of the catalytic activities of the investigated catalysts in the hydrogenation of LA to MTHF has been included in Table 2. Reactions were carried out under microwave irradiation for a quick screening and optimisation of reaction conditions in view of translating optimised results into a continuous flow system equipped with a back pressure regulator able to mimick temperatures and pressures achieved under microwave batch reactions. ${ }^{15}$ FA efficiently decomposed under microwave mild heating to provide the needed hydrogen for the hydrogenation reaction based on previous work by the group on FA-assisted lignin depolymerisation. ${ }^{9}$ Optimised results pointed out the excelling activity of the Cu MINT, with a 0.51 wt.\% $\mathrm{Cu}$ loading, which provided almost quantitative conversion of LA in 30 min reaction. Selectivity was complete to hydrogenated products, namely PDO and MTHF (Table 1). 
Table 2. Catalytic activity of investigated catalysts in the liquid phase microwaveassisted hydrogenation of LA to MTHF. ${ }^{[a]}$

\begin{tabular}{lccccc}
\hline Catalyst & $\begin{array}{c}\text { Conv } \\
(\mathrm{mol} \%)\end{array}$ & \multicolumn{4}{c}{ Selectivity (mol\%) } \\
\cline { 3 - 6 } & & MTHF & GVL & PDO & Others $^{\text {b }}$ \\
\hline Blank (no cat.) & - & - & - & - & - \\
\hline Ru-Starbon ${ }^{\circledR}$ & $<30$ & $<50$ & 20 & - & $>30$ \\
Rh-Starbon ${ }^{\circledR}$ & 69 & 90 & - & - & 10 \\
Pd-Starbon ${ }^{\circledR}$ & 64 & 88 & - & - & 12 \\
Cu-MINT & $>90$ & 75 & & 25 & - \\
5\%Pd/C & 78 & 92 & - & - & 8 \\
\hline
\end{tabular}

[a] Reaction conditions: $0.1 \mathrm{~mL}$ LA, $0.3 \mathrm{~mL} \mathrm{FA}, 0.1 \mathrm{~g}$ catalyst, $150^{\circ} \mathrm{C}, 30 \mathrm{~min}$ microwave irradiation, $300 \mathrm{~W}$ (maximum power output). ${ }^{[\mathrm{b}]}$ other products obtained in the reaction included angelicalactone (AL) from FA-catalysed dehydration of LA as well as pentanoic acid (PA) and 4-hydroxyvaleric acid (HVA) from hydrogenation of LA.

Comparatively, Starbon ${ }^{\circledR}$ supported metals provided reduced activities but improved selectivities to MTHF. Interestingly, the use of a commercial $5 \% \mathrm{Pd} / \mathrm{C}$ catalyst gave high selectivities to MTHF at relatively high conversions (78\%, Table 2). Lower FA quantities in the system $(<0.3 \mathrm{~mL})$ also led to low activities in the hydrogenation even at longer times of reaction (e.g. $<30 \%$ conversion for Pd Starbon ${ }^{\circledR}$ after $60 \mathrm{~min}$ reaction using $0.1 \mathrm{~mL} \mathrm{FA).} \mathrm{Reuses} \mathrm{of} \mathrm{batch} \mathrm{microwave} \mathrm{reactions} \mathrm{of} \mathrm{Cu}-\mathrm{MINT}$ and $5 \% \mathrm{Pd} / \mathrm{C}$ showed no apparent leaching of metal into solution, with catalysts preserving over $90 \%$ of their initial activity after 3 uses (Figure 2). Selectivities did not significantly change upon reuse to those summarised for the fresh catalysts in Table 1. The stability of $\mathrm{Cu}-\mathrm{MINT}$ under microwave irradiation conditions seemed to be related to the unique characteristics and stability of the materials, in good agreement with recently reported similar highly stable and active $\mathrm{Cu}$ phyllosilicate catalysts. ${ }^{15}$ A closer look on characterisation of the investigated materials pointed no direct relationship between NP size, metal content or textural properties with catalytic activities. In any case, a combination of $\mathrm{Cu}^{+}$and most importantly $\mathrm{Cu}^{0}$ species in conjunction with the MINT nanostructure is believed to be responsible for the high catalytic activity and stability in the materials as shown in recently developed analogous $\mathrm{Cu}$-silica based 
systems. ${ }^{15} \mathrm{Cu}^{+}$and $\mathrm{Cu}^{0}$ species are formed during the reaction via in-situ reduction of $\mathrm{CuO}$ species by the evolved hydrogen from formic acid decomposition. The formation of these species to some extent under microwave irradiation was found to be sufficient to promote the reaction to high substrate conversion at a moderate to high selectivity to MTHF (Table 1).

Only optimum catalysts ( $\mathrm{Cu}-\mathrm{MINT}$ vs $5 \% \mathrm{Pd} / \mathrm{C}$ commercial catalyst) were further considered under flow conditions and compared with a commercial $\mathrm{CuO} / \mathrm{Al}_{2} \mathrm{O}_{3}$ catalyst. A simple flow chemistry equipment (X-Cube, Thalesnano inc., suppporting information) was utilised to translate optimised microwave batch results. Flow reactors offer important advantages as compared to batch chemistries including an improved control of reaction parameters, quick and efficient reagents mixing, shorter times of reactions (similar to microwave batch reactions) as well as enhanced heat and mass transfer which can significantly promote catalysed processes. ${ }^{16,17}$

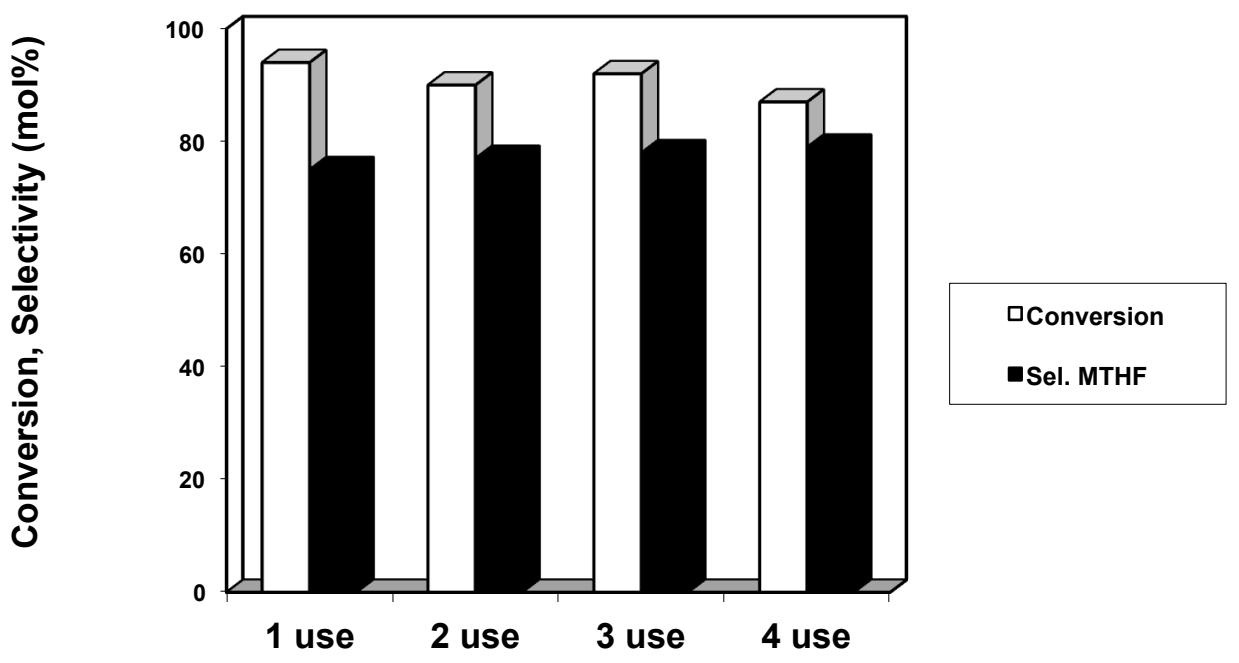

Figure 2. Reuses of Cu-MINT in the conversion of levulinic acid to MTHF under microwave irradiation. Reaction conditions (each run): $0.1 \mathrm{~mL} \mathrm{LA}, 0.3 \mathrm{~mL}$ FA, $0.1 \mathrm{~g}$ catalyst, $150^{\circ} \mathrm{C}, 30 \mathrm{~min}$ microwave irradiation. Upon reaction completion, the catalyst was filtered off, washed throughly with acetone and ethanol and subsequently oven-dried at $120^{\circ} \mathrm{C}$ prior to another use with fresh reagents. 
Figure 3 summarises the main optimised results under continuous flow conditions. The activities of $\mathrm{Cu}-\mathrm{MINT}$ and commercial $5 \% \mathrm{Pd} / \mathrm{C}$ were found to be very similar under the investigated flow conditions (Cu-MINT 79 vs $73 \% \mathrm{Pd} / \mathrm{C}$ ) but remarkably different selectivities to MTHF were observed in both systems. Only two main products (MTHF and PDO) were obtained in 60 and 40\% selectivity, respectively, under the investigated conditions for $\mathrm{Cu}$ MINT. Comparably, almost equally active $5 \% \mathrm{Pd} / \mathrm{C}$ system gave rise to a number of hydrogenation products including $\mathrm{PDO}$, pentanoic acid (PA) and 4-hydroxyvaleric acid (HVA), with a low selectivity to MTHF $(<30 \mathrm{~mol} \%)$.

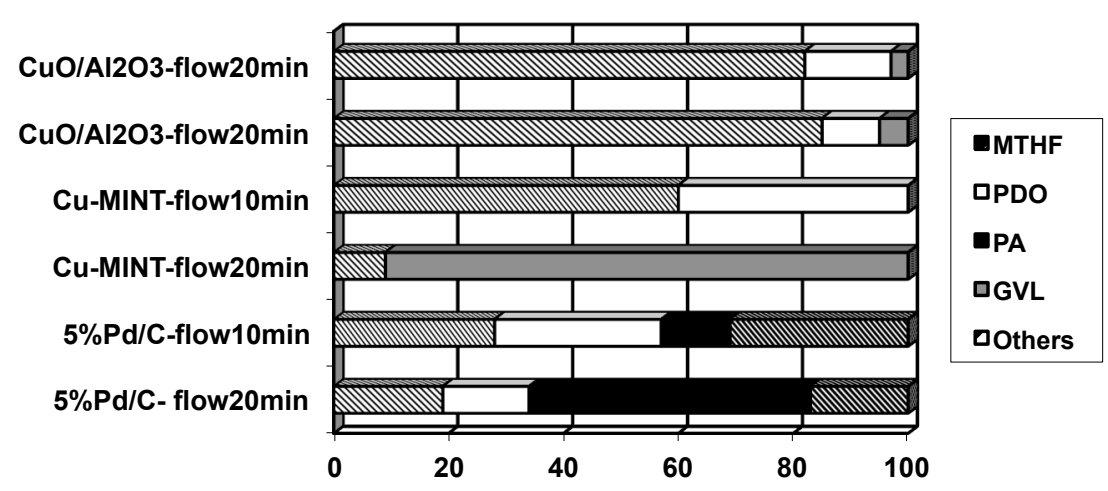

\section{Selectivity (mol\%)}

Figure 3. Selectivity to products (mol\%) in $\mathrm{Cu}-\mathrm{MINT}$ and $5 \% \mathrm{Pd} / \mathrm{C}$ catalysed conversion of LA. Reaction conditions: $0.1 \mathrm{~mL} \mathrm{LA}, 0.3 \mathrm{~mL} \mathrm{FA}, 150^{\circ} \mathrm{C}$, flow rate $0.1 \mathrm{~mL} \mathrm{~min}{ }^{-1}$, $150^{\circ} \mathrm{C}$, feed/catalyst contact time: $1 \mathrm{~min} ; 0.25 \mathrm{~g}$ catalyst.

The deactivation and leaching of the catalysts under the investigated flow conditions was subsequently studied. Results summarised in Figure 3 and Table 3 clearly demonstrated that the $\mathrm{Cu}$ MINT catalyst was not stable under flow conditions, significantly deactivating with time on stream (Table 3). Leaching studies of the catalyst showed important quantities of leached $\mathrm{Cu}(62 \mathrm{ppm})$ in solution which in fact possessed a light blue colour typical of $\mathrm{Cu}^{2+}$ species, supporting the deactivation of the catalyst by leaching. This is likely to be related to the solubility of $\mathrm{Cu}^{2+}$ species in acidic media, ${ }^{18}$ 
which can be particularly enhanced under continuous flow circulation of FA over Cu-MINT.

Interestingly, the decrease in conversion in the $\mathrm{Cu}$ MINT was also accompanied by a remarkable switch in selectivity towards a $>90 \mathrm{~mol} \%$ production of GVL (Figure 3, Table $3 \mathrm{Cu}-\mathrm{MINT}$-flow20min). Comparatively, the commercial 5\% $\mathrm{Pd} / \mathrm{C}$ catalyst preserved almost intact its activity with time on stream, with however unexpectedly altered selectivities to products in the hydrogenation reaction (Figure 3, $5 \% \mathrm{Pd} / \mathrm{C}$-flow20min). An unexpected $50-70 \%$ selectivity to $\mathrm{PA}$, at even reduced selectivities to MTHF ( $<20 \mathrm{~mol} \%)$ seemed to point out that ring-opening (FA mediated) followed by hydrogenation on Pd sites to PA is the preferred pathway from GVL at increasing times of stream (Scheme 3), as similarly reported by Serrano-Ruiz et al. for $\mathrm{Pd} / \mathrm{Nb}_{2} \mathrm{O}_{5}$ catalysts ${ }^{19}$. No $\mathrm{Pd}$ leaching could be quantified by ICP MS under the investigated conditions (see supporting information).

Table 3. Catalytic activity of investigated catalysts in the liquid-phase continuous flow conversion of LA. ${ }^{\mathrm{a}}$

\begin{tabular}{lccccc}
\hline Catalyst & $\begin{array}{c}\text { Time } \\
\text { (min) }\end{array}$ & $\begin{array}{c}\text { Conv } \\
(\mathrm{mol} \%)\end{array}$ & \multicolumn{3}{c}{ Selectivity (mol\%) } \\
\cline { 4 - 6 } & & & MTHF & PDO & Others \\
\hline $\mathrm{Cu}-\mathrm{MINT}$ & 10 & 79 & 60 & 40 & - \\
& 20 & 20 & 9 & - & $91^{\mathrm{D}}$ \\
$5 \% \mathrm{Pd} / \mathrm{C}$ & 30 & 13 & 5 & - & $95^{\mathrm{D}}$ \\
& 10 & 73 & 28 & 29 & $43^{\mathrm{c}}$ \\
& 20 & 67 & 19 & 18 & $63^{\mathrm{c}}$ \\
$13 \mathrm{wt} \% \mathrm{CuO} / \mathrm{Al}_{2} \mathrm{O}_{3}$ & 30 & 70 & 20 & 10 & $70^{\mathrm{c}}$ \\
& 10 & 55 & 82 & 15 & $<5$ \\
& 20 & 47 & 85 & $<15$ & $<5$ \\
& 30 & 44 & 80 & 15 & 5
\end{tabular}

${ }^{[a]}$ Deactivation studies of investigated systems in the continuous flow conversion of LA. Reaction conditions: $0.1 \mathrm{~mL} \mathrm{LA}, 0.3 \mathrm{~mL}$ FA, $150^{\circ} \mathrm{C}$, flow rate $0.1 \mathrm{~mL} \mathrm{~min}{ }^{-1}$, feed/catalyst contact time: $1 \mathrm{~min} ; 0.25 \mathrm{~g}$ catalyst. ${ }^{[\mathrm{b}]}$ Main product observed was GVL; ${ }^{[\mathrm{c}]}$ Main reaction products were PA (major) and HVA (minor).

As comparison to these selected systems, an additional commercial $13 \mathrm{wt} \% \mathrm{CuO} / \mathrm{Al}_{2} \mathrm{O}_{3}$ catalyst was found to be slightly more stable and moderately active 
(Table 3), providing a high selectivity to MTHF (>80\%) under the investigated flow conditions. However, a certain $\mathrm{Cu}^{2+}$ leaching $(<20 \mathrm{ppm})$ was also observed for this catalyst after $1 \mathrm{~h}+$ reaction and continuous flow conditions (increasing also with time on stream), which entailed a progressive catalyst deactivation with time (Table 3 ). The activity of $\mathrm{CuO} / \mathrm{Al}_{2} \mathrm{O}_{3}$ catalyst was 3-4 times superior to that of $\mathrm{Cu}-\mathrm{MINT}$ after $30 \mathrm{~min}$ under flow conditions, which obviously reflects on the significantly larger $\mathrm{Cu}$ content in $\mathrm{CuO} / \mathrm{Al}_{2} \mathrm{O}_{3}$ as compared to $\mathrm{Cu}-\mathrm{MINT}$ ( $>20$ times). In summary, the reported results seem to confirm that $\mathrm{Cu}$ based catalysts are not particularly stable under combined continuous flow and acidic conditions.

In any case, an interesting discussion could be built up from the reported findings under continuous flow conditions as included in Scheme 3 with clearly different pathways (highlighted by bold arrows) for $\mathrm{Cu}-\mathrm{MINT}$ and noble metal containing materials.

Starting from $\mathrm{Cu}$-based materials, PDO is believed to be the key intermediate in the production of MTHF. This compound seemed to be produced in our systems via a two step reaction from LA, first to AL and then subsequent hydrogenation to PDO (Scheme 3). These chemistries have also been previously reported to be catalysed by stabilised copper chromite materials. ${ }^{8,20}$

AL can indeed be easily obtained by dehydration of levulinic acid at temperatures over $150^{\circ} \mathrm{C} .{ }^{19}$ FA promotes this dehydration step even at lower temperatures in our proposed system. This compound can also simply polymerise under strong acidic conditions leading to complex solid structures ${ }^{21}$ which were interestingly not found in our system (most probably due to the decomposition of FA and acidolytic cleavage of plausibly formed oligomers). No evidences were obtained either for the direct hydrogenation of LA to GVL or to HVA using Cu-MINT systems. PDO can be 
then readily converted into MTHF via dehydration under heating and/or promoted by FA due to the thermal instability of the compound. ${ }^{20}$ These observations are both applicable to microwave batch and continuous flow conditions. Interestingly, GVL was the major product ( $>90 \%$ selectivity) observed upon deactivation and leaching of $\mathrm{Cu}-\mathrm{MINT}$ (Figure 2, $\mathrm{Cu}$ MINT flow20min). $\mathrm{Cu}$ leaching into solution significantly reduces FA decomposition therefore less hydrogen is generated. Less hydrogen generated together with a significant decrease of $\mathrm{Cu}$ sites available for the hydrogenation process lead to a maximised production of GVL.

Comparatively, a different pathway can be observed to be promoted by noble-metal containing catalysts (e.g. Pd, Ru, Rh, Scheme 3 bottom). GVL, detected in supported noble-metal catalysed reactions, was the key intermediate in these processes. This compound could be generated from three competitive processes (Scheme 3, bottom). AL was again produced (as observed for all $\mathrm{Pd}, \mathrm{Ru}$ and $\mathrm{Rh}$ systems) and further hydrogenated to GVL, in good agreement with previous literature reports. ${ }^{19,22,23}$

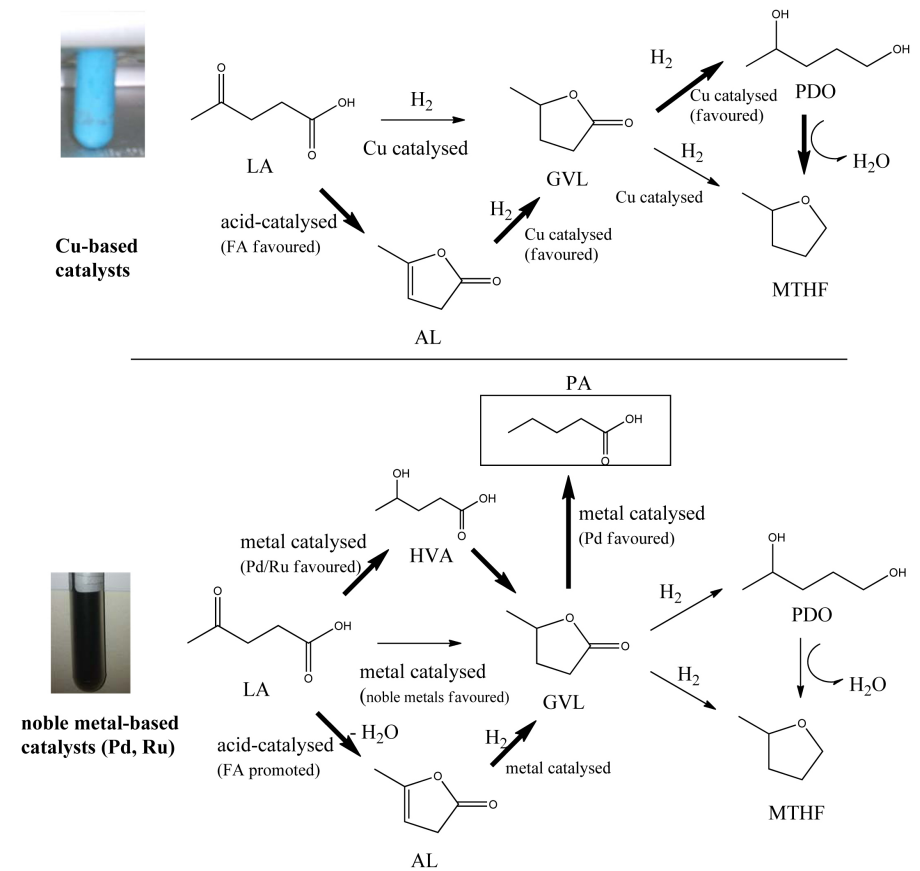

Scheme 3. Proposed reaction pathways in the investigated $\mathrm{Cu}$-based (top) and noble metal (bottom) catalytic systems identifying key steps (bold arrows) and favoured/promoted catalysed chemistries. 
However, the competitive production of GVL was also favoured via hydrogenation of the carbonyl group at the 4-position of LA to HVA on noble metal sites (with in-situ generated hydrogen from FA decomposition, Scheme 3 bottom) followed by dehydration/cyclisation to GVL. These claims can be supported by the important quantities observed of HVA in the Pd or Ru catalysed hydrogenation of LA (see supporting information), in good agreement also with literature reports for Pd and Ru catalysts. ${ }^{22}$ Upon GVL formation, this intermediate was subsequently hydrogenated to either PA or PDO, clearly under competitive pathways. Short times of reaction in batch seem to favour the formation of PDO (and then MTHF via dehydration) while PA was obtained at increasing quantities at longer times of reaction under flow conditions.

\section{Conclusions}

In conclusion, we have reported a number of supported nanoparticle systems $(\mathrm{Cu}$ vs noble metals) that were able to provide interesting insights into reaction pathways for the production of valuable compounds (e.g. MTHF, PDO and PA) from LA hydrogenation under both microwave batch and continuous flow conditions. These findings are envisaged to set the basics to the design of more stable and highly efficient nanocatalytic systems for continuous flow processing of biomass-derived platform molecules to valuable chemicals and biofuel precursors.

\section{Acknowledgments}

The authors thank the Spanish MINECO (Project CTQ2011-28954-C02-01 for financial support. E.S. acknowledges financial support from JCI 2008-2165. RL gratefully acknowledges Ministerio de Ciencia e Innovacion, Gobierno de España for 
the concession of a Ramon y Cajal contract (RYC-2009-04199). Manuel Ojeda and Antonio Pineda are gratefully acknowledged for support during the studies conducted in this work. Jose M. Bermudez acknowledges the support received from the CSIC JAE Program.

\section{References}

1 a) T. Werpy and G. Petersen, in Top value added chemicals from biomass. Vol. 1. Results of screening for potential candidates from sugars and synthesis gas, U.S. Dep. Energy, Off. Sci. Tech. Inf., 2004. http://www.nrel.gov/docs/fy04osti/35523.pdf; b) J.J. Bozell, G.R. Petersen, Green Chem., 2010, 12, 539-554.

2 a) A. Corma, S. Iborra, A. Velty, Cherm. Rev, 2007, 107, 2411-2502; b) G.W. Huber, A. Corma, Angew. Chem. Int. Ed., 2007, 46, 7184-7201; c) J.H. Clark, R. Luque and A.S. Matharu, Ann. Rev. Chem. Biomol. Eng., 2012, 3, 183-207.

3 M. Pagliaro, R. Ciriminna, H. Kimura, M. Rossi and C.D. Pina, Angew. Chem. Int. Ed., 2007, 46, 4434-4440.

4 a) Y. Roman-Leshkov, C.J. Barret, Z.Y. liu and J.A. Dumesic, Nature, 2007, 447, 982-985; b) J.Q. Bond, D.M. Alonso, D. Wang, R.M. West and J.A. Dumesic, Science, 2010, 327, 1110-1114.

5 a) J.N. Chheda, G.W. Huber and J.A. Dumesic, Angew. Chem. Int. Ed., 2007, 46, 7164-7167; b) S.F. Paul, US Pat. 1997, 5,697,987; c) http://www.afdc.energy.gov/afdc/fuels/emerging_pseries.html

6 V. Pace, P. Hoyos, M. Fernandez, J.V. Sinisterraa and A.R. Alcantara, Green Chem., 2010, 12, 1380-1382.

7 a) X.Du, Q.Bi, Y.Liu, Y. Cão, H. He and K. Fan, Green Chem., 2012, 14, 935-939;

b) P.P. Upare, J. Lee, Y.K. Hwang, D.W. Hwang, J.Lee, S.B. Halligudi, J. Hwang and J. Chang, ChemSusChem, 2011, 4, 1749-1752.

8 F.A. Geilen, B. Engendahl, A. Harwardt, W. Marquardat, J. Klankermayer and W. Leitner, Angew. Chem., 2010, 122, 5642-5646.

9 a) A. Toledano, L. Serrano, A. Pineda, A.M. Balu, R. Luque and J. Labidi, ChemSusChem. 2013, DOI: 10.1002/cssc.201200755; b) A. Toledano, L. Serrano, J. Labidi, A.M. Balu, A. Pineda and R. Luque, ChemCatChem., 2013, DOI: 10.1002/cctc.201200616.

10 L. Deng, J. Li, D. Lai, Y. Fu and Q. Guo, Angew. Chem. Int. Ed., 2009, 48, 65296532.

11 a) B. Loges, A. Boddien, H. Junge and M. Beller, Angew. Chem. Int. Ed., 2008, 47, 3962-3965; b) A. Boddien, B. Loges, H. Junge and M. Beller, ChemSusChem, 2008, 1, 751-758.

12 a) C. Gonzalez-Arellano, A.M. Balu , R. Luque and D.J. Macquarrie, Green Chem., 2010, 12, 1995-2002; b) C. Gonzalez-Arellano, R. Luque and D.J. Macquarrie, Chem. Commun., 2009, 30, 4581-4583.

13 R. Luque, J.H. Clark, K. Yoshida and P.L. Gai, Chem. Commun., 2009, 35, 53055307.

14 V. Budarin, J.H. Clark, J.J.E. Hardy, R. Luque, D.J. Macquarrie, K. Milkowski, S.J. Tavener and A.J. Wilson, Angew. Chem. Int. Ed., 2006, 45, 3782-3786. 
15 J. Gong, H. Yue, Y. Zhao, S. Zhao, L. Zhao, J. Lv and S. Wang, J. Am. Chem. Soc. 2012, 134, 13922-13925.

16 T.N. Glasnov and C.O. Kappe, Chem. Eur. J. 2011, 17, 11956-11968.

17 D. Cantillo, M. Baghbanzadeh and C.O. Kappe, Angew. Chem. Int. Ed., 2012, 51, 10190-10193.

18 a) D. Mantzavinos, R. Hellendrand, A.G. Livingston and I.S. Metcalfe, Appl. Catal. B, 1996, 7, 379-396; b) J. Levec and A. Pintar, Catal. Today, 1995, 24, 51-58.

19 J.C. Serrano-Ruiz, D. Wang and J.A. Dumesic, Green Chem., 2010, 12, 574577.

20 D.C Elliot and J.G. Frye, US Pat. 1999, 5,883,266 and references therein.

21 P.M. Ayoub and J.P. Lange, WO 2008/142 127.

22 M. G. Al-Shaal, W.R.H. Wright and R. Palkovits, Green Chem., 2012, 14, 12601263.

23 A.M.R. Galletti, C. Antonetti, V. De Luise and M. Martinelli, Green Chem., 2012, 14, 688-694. 